\title{
Study of the Shock Wave Effect on the Deformation of the Vehicle Bottom Using Deformable Energy Absorbers
}

\author{
L. STARCZEWSKI, M. GMITRZUK, D. DANIELEWICZ, K. SZCZEŚNIAK, R. NYC \\ Military Institute of Armoured and Automotive Technology, Department of Material Armament and Equipment Expertise, \\ 1 Okuniewska Str., 05-070 Sulejówek, Poland, E-mail: witpis@witpis.eu
}

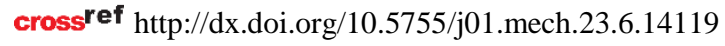

\section{Introduction}

Explosives buried in the ground such as mines or Improvised Explosive Devices (IED) present a particular threat to Light Armoured Vehicles (LAV). Compared with heavier armoured vehicles, such as tanks, light armoured vehicles are particularly vulnerable to this form of attack. Providing LAVs with add-on armour is not always a good solution because of their limited carrying capacity. To keep up with the required level of protection, extensive research is carried out on the use of composite and metallic materials, as well as their configuration within the structure, to produce the most effective energy absorbing shield possible for a given vehicle [1].

The studies on deformable energy-absorbing elements were presented, inter alia, in references [2-5] reporting the findings of analyses of the effects brought about by detonated charges in model energy absorbing systems fabricated of metal 3D structures. The tests were smallscale experiments, with laboratory samples using small energy equivalents. The above-cited references indicate that the purpose of the $3 \mathrm{D}$ structures placed between two metal plates is to convert the energy of explosion into the energy of deformation of the 3D structures. It is, however, correct for low detonation energies, and applicable where a low-weight shield is required.

The shape of the protective shield has a significant effect on the dissipation of the detonation energy of blowing charges. At present, V-shaped hulls are widely used in wheeled armoured personnel carriers. As shown, e.g., in ref. [1], the shape has a significant effect on the dissipation of the detonation wave arising in front of the vehicle. This chassis shape is usually used in LAVs due to their high clearance. Because of their specific construction, low clearance, and drivetrain design, caterpillar vehicles have limited capability of using V-shaped deflectors. In addition, the vehicles have a higher resistance to kinetic ammunition and are heavier while their ground unit pressure is minimised [6]. Therefore, weight added to the vehicle has a smaller effect on vehicle mobility. This allows shields to be used, fabricated of heavier and more rigid composite materials, but with sufficient plastic and elastic deformability, making use of structures of composite materials placed between the bottom of the vehicle hull and the crew compartment. A review of the literature indicates that vehicles with properly designed, heavier energy absorbing shields fabricated of appropriately selected materials are more resistant to higher exposure levels. This follows from the fact that they reduce the impact forces acting on the basic hull of the vehicle, and thereby directly influence crew injury rates.
Irrespective of the military aspects, the research covers energy absorbing shields that can be used in civilian industries where gas detonation hazards occur, often combined with the outburst of solids, e.g. in mining operations where deposits are accompanied by methane, in drilling platforms or for the protection of government buildings against terrorist attacks [7, 8].

\section{Objective of the study}

The objective of the study is to find optimal design solutions to protect the vehicle's lower hull in order to reduce the energy pulse of the shock wave penetrating into the vehicle interior down to the acceptable parameter values as provided by the NATO AEP-55 vol. 2 document [9]. It is assumed that the principal components of the protection systems include an appropriately shaped vehicle bottom with incorporated elements absorbing the energy of the propagating shock wave resulting from charge detonation.

The results of the tests presented below refer to recorded deformations of models of a planar module of the spatial vehicle bottom structure with a surface area of 1 $\mathrm{m} 2$, fitted with an $830 \times 830 \times 80 \mathrm{~mm}$ absorber. The tests involved absorbers with different absorbabilities of the shock wave energy. It was assumed for testing purposes that the energy released in detonation of $1.5 \mathrm{~kg}$ TNT was constant throughout the tests.

\section{Testing methods and materials}

Upon reaching a barrier, the shock wave deforms it. If the barrier material has elastic- plastic properties, the deformation is a sum of elastic and plastic deformations. As the shock wave decays, only plastic deformations remain in the barrier material. Most literature reports assume that the amount of the deformation is the measure of absorption of the shock wave energy by the barrier material. This view is an over-simplification, because a part of the energy is consumed in elastic deformation. In order to learn which part of the shock wave energy is consumed in elastic and which in plastic deformation, a measurement method described in the US TOP 2-1-007 procedure [10], referred to as the comb gage method, was used for tests.

Essentially, the testing attempted to obtain information on the absorbability of the shock wave energy by the absorbers tested using a measurable parameter. For that purpose, it was decided to use the method described above. The method is an indirect measurement method, i.e., the measurement of the total deformation of the barrier follows from the comb gage deformation. As the method assumes 
that deformable lightweight elements of low elasticity modulus are used, comb gages with easily deformable rods of suitable geometry and length were fabricated of thin aluminium sheet (Fig. 1, c). The comb gages were placed over the tested samples so that the longest rod touched the surface of the element subject to deformation (Fig. 2, a). This allowed for a "post factum" analysis of the total deformation brought about by the shock wave in the upper element of the system. The actual result of the test is the difference between the measured heights [in $\mathrm{mm}$ ] of the maximum deformation recorded on the comb gage in the form of deformed rods for the reference system (with no absorber) and the system with absorber. The difference is the measure of the shock wave energy absorbed by the tested absorber.

Measurement methods for dynamic distortions of structures are known. They include the following methods: acceleration sensors, laser beams, fibre Bragg grating, etc.
It was recognised, however, that for the assumed aim of the research, the comb-straining method, which is described in document TOP 2-1-007, is the easiest, although not very accurate, but is characterised by minimum data loss.

The test was conducted on blasting grounds with the use of a research station (Fig. 1, a, b), which allows for putting the tested systems over an explosive charge and fixing measuring instruments. The testing station was a 2800x4200x2200 mm steel frame of about $3500 \mathrm{~kg}$ in weight, placed over a steel detonation plate with a hole for the blowing charge (Fig. 1, b). The use of the detonation plate with a hole ensured that the experiments were reproducible when charges of the same weight were used. Steel detonation plates with a hole are used in experiments performed in accordance with the NATO standard presented in the AEP-55 vol. 2 document, in order to guide all the energy of the detonated charge.

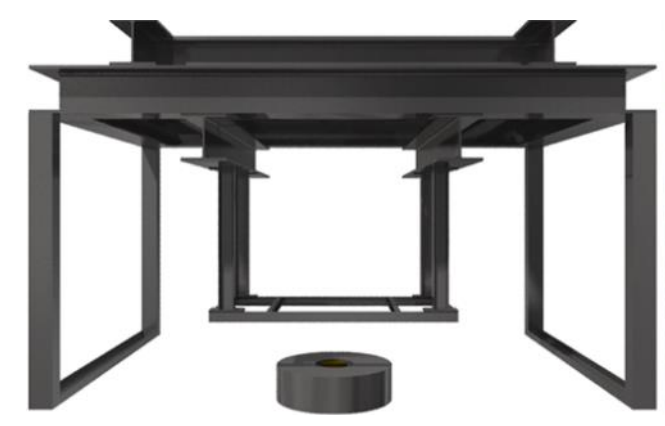

a

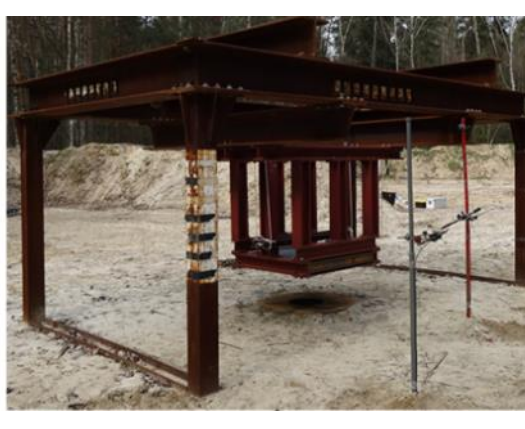

b

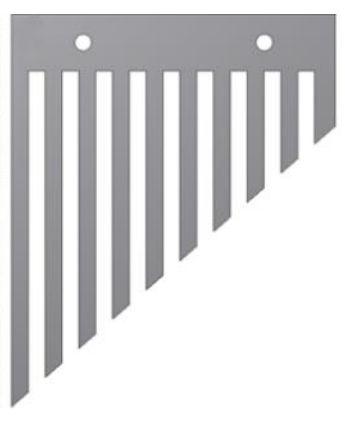

c

Fig. 1 Testing station for testing the resistance of barriers to detonation wave: a - concept, b - constructed testing station with the detonation plate base, $\mathrm{c}$ - deformable comb gage recording the amount of the barrier deformation

The tested system consisted of two $1000 \times 1000$ mm elements fabricated of Armox 500T armour plates with the following respective thicknesses: $6 \mathrm{~mm}$ for the lower plate on the charge side and $8 \mathrm{~mm}$ for the upper plate. About $80 \mathrm{~mm}$ thick $830 \times 830 \mathrm{~mm}$ absorbers were placed between these elements. In the reference system, there was air between the plates. The tested systems were placed in a holder (Fig. 1, b).

\section{Methodology and research material of numerical models}

The research assumes the following research methodology. Phase 1 is the construction of a numerical model based on measurements, used materials, and assumed construction of the test model. Phase 2 is the test model simulation for the value of a $1.5 \mathrm{~kg}$ TNT charge generated by the explosive charge. Phase 3 is the comparison of the obtained results for numerical model verification. This procedure allows for obtaining a numerical model which may be used for correct interpretation of straining and strength processes occurring in the tested model due to impulsing effects. The assumed methodology is proper, since it allows for searching for absorber's material and design solutions with optimal rigidity and attenuation of impact wave energy caused by the detonation of the explosive charge, particularly for systems with complex material and design structure, which are characterised by strength parameters which are difficult to describe in a numerical model. The programme of tests to verify the numerical model was established in testing grounds conditions (Fig. 1).

The research conducted at the Institute of Industrial Organic Chemistry allowed for verification of numerical models of the entire phenomenon with the consideration of a reference barrier.

Numerical research utilised a geometric model, which is a reflection of the actual system consisting in a layered structure of $6 \mathrm{~mm}$ and $8 \mathrm{~mm}$ ARMOX 500T armour steel plates. The analyses and computer simulations assumed the use of a $1.5 \mathrm{~kg}$ explosive charges. The model was created in Euler's environment, where the propagation of shock wave after an explosion is observed. The numerical models of steel plates, along with the ballast and distance, were created in Lagrange's environment.

The analysis of the explosive charge detonation products' pressure impact on the structure utilises a method which consists in a description of the movement of gases over Euler's space and its Fluid-Structure Interaction (FSI).

Preservation of the total energy of the system in Euler's environment possible to use a scheme based on the Van Leer advection method.

The coupling between the finite elements Lagrange and Euler environments was achieved thanks to the program LS-DYNA.

The numerical model of air area corresponded to the $800 \times 1600 \times 1600 \mathrm{~mm}$ dimensions. The finite element dimension to $10 \mathrm{~mm}$ was assumed. Two million finite elements were achieved. Dimensions of the explosive in 
accordance with the experiment were adopted (cylinder with a diameter of $150 \mathrm{~mm}$ and height $50 \mathrm{~mm}$ ). The explosive was placed in a model steel plate corresponds to the dimensions the blasting plate according to the AEP-55 [9].

The boundary conditions of numerical models of the stand was adopted in accordance with the experiment tests. To reduce the number of finite elements were modeled only a part of the frame located above the explosives and then it was loaded with the additional weight of 3.5 tonnes.
Numerical models of the absorbers and reference system placed between the I-beam with a large width of the flange (120 HEM) and thus receive all the degrees of freedom of the two opposite sides of the panel.

Strength parameters and material parameters for Armox armour steel and for the explosive charge are presented in Table 1 and 2. For absorbers, due to their complex structure and used materials with variable rheology, it was assumed, for simplicity reasons, that it is the volume between armour steel plates filled with elastomer with properties similar to hard polyurethane.

Table 1

Strength parameters of Armox 500T armour steel

\begin{tabular}{|c|c|c|c|c|c|c|c|c|}
\hline Material & $\rho, \mathrm{kg} / \mathrm{m}^{3}$ & $A, \mathrm{MPa}$ & $B, \mathrm{MPa}$ & $C$ & $n$ & $m$ & $T r, \mathrm{~K}$ & $T m, \mathrm{~K}$ \\
\hline $\begin{array}{c}\text { Armox } \\
\text { 500T }\end{array}$ & 7850 & 1470 & 702 & 0,00549 & 0,199 & 0,81 & 293 & 1800 \\
\hline
\end{tabular}

Table 2

Material parameters for the TNT explosive material

\begin{tabular}{|c|c|c|c|c|c|c|c|c|c|}
\hline Explosive & $\rho_{0}, \mathrm{~g} / \mathrm{cm}^{3}$ & $A, \mathrm{GPa}$ & $B, \mathrm{GPa}$ & $p_{C J}, \mathrm{GPa}$ & $R_{1}$, & $R_{2}$, & $E_{0}, \mathrm{GPa}$ & $D_{s r}, \mathrm{~m} / \mathrm{s}$ & $\omega$, \\
\hline $\mathrm{TNT}$ & 1,63 & 371,2 & 3,231 & 21,0 & 4,15 & 0,95 & 7,0 & 6930 & 0,3 \\
\hline
\end{tabular}

The strength parameters of Armox 500T armour steel were described by the Johnson-Cook,s model (1). The model is an empirical and the most popular equation which describes the strength of materials in terms of strain, straining speed, and temperature.

$$
\begin{aligned}
& \sigma(\varepsilon, \dot{\varepsilon}, T)= \\
& =\left(A+B \varepsilon^{n}\right)\left(1+C \ln \left(\frac{\dot{\varepsilon}}{\dot{\varepsilon}_{0}}\right)\right)\left(1-\left(\frac{T-T_{R}}{T_{m}-T_{R}}\right)^{m}\right),
\end{aligned}
$$

where $A$ is yield strength for reference parameters; $T_{R}$ temperature and $\left(\varepsilon_{0}\right)^{\cdot}$ straining speed; $B, n$ is strain hardening ratio; $C$ is dynamic hardening ratio; $T_{m}$ - melting point.

The explosive charge detonation process utilises the equation of state EOS JWL (2):

$$
\begin{aligned}
& p=A\left(1-\frac{\varpi}{R_{1}} \frac{\rho}{\rho_{0}}\right) e^{-R_{1} \frac{\rho_{0}}{\rho}}+B\left(1-\frac{\varpi}{R_{2}} \frac{\rho}{\rho_{0}}\right) e^{-R_{2} \frac{\rho_{0}}{\rho}}+ \\
& +\omega E \frac{\rho}{\rho_{0}}
\end{aligned}
$$

where $p$ is pressure; $\rho$ is density; $E$ is detonation energy; $A$, $B, R_{1}, R_{2}, \omega$ are explosive charge parameters.

During the calculation the following were determined: the shift of nodes, strain of individual elements, etc. In order to distinguish the points of the upper and lower plate this study will use the respective indices $U$ and $L$.

The scope of numerical tests included the impact of the explosive charge on the protective panel for the following variants:

a) base panel without an absorber,

b) base panel with $\mathrm{A} 1$ absorber,

c) base panel with A3 absorber,

d) base panel with A2/A4 absorber.

All calculation variants utilise identical mass and location of the charge. The tested absorbers were made from the same materials, but their inner designs are different.

The strength parameters of the absorber components were adopted from the material database available in the LS-DYNA program. Material composition of numerical models corresponded to materials such as glass composites, carbon composites, polyurethane, and aramid composites.

\section{Experimental results}

The tests of energy absorbability were carried out for three material and structural solutions. The absorbers were marked A1, A2, A2/A4.

The shock wave was generated by explosion of a $1.5 \mathrm{~kg}$ TNT blowing charge under the tested system with energy absorber, located $450 \mathrm{~mm}$ above the charge. The value simulated the distance of the vehicle bottom from the ground.

The maximum and minimum deformations of the comb gage were measured, and the measured values were subsequently referred to the total length of the maximum section of the non-deformed comb gage. Example appearance of the comb gage before and after the test is shown in Figs. 2, a and b.

Each experiment was followed by measurements of the permanent plastic deformations in the tested system components fabricated of upper and lower armoured plates.

The measurement results are presented in Table 3 and Figs. 3 and 4. The tests showed that the shock wave energy produced by the detonation of $1.5 \mathrm{~kg}$ TNT resulted in the maximum deformation of the measurement section (rod) of the comb gage for the reference energy absorbing barrier (P1). The recorded amount of deformation $(101.3 \mathrm{~mm})$ proves that high energy was transferred to the comb gage (Fig. 3, a) in the first phase of deformation of the $8 \mathrm{~mm}$ thick upper armour plate.

This resulted from the fact that the $6 \mathrm{~mm}$ thick lower plate, strained by the explosive force, transferred 
momentum to the $8 \mathrm{~mm}$ thick upper plate when they touched. Since that moment, both plates were being strained.

The maximum strain was the total of elastic and plastic strain of the plates material. When the shock wave faded, the plates retained only plastic strain.

Reference system (without absorber) registered (on the comb) a maximum strain of $101.3 \mathrm{~mm}$ (Fig. 3 ,a), and when the process ended, the measured strain amounted to $22 \mathrm{~mm}$ - plastic strain (Table 3 ).

In systems (shields) with A1, A3, and A2/A4 absorbers, the measured maximum strain of measured segments amount to $79.1 \mathrm{~mm}, 86.9 \mathrm{~mm}$, and $82.3 \mathrm{~mm}$ respectively. The lowest strain value was achieved by the A1 absorber (Fig. 3, b). As compared to the strain achieved for the reference shield (Fig. 3, a), a 22\% decrease of the total strain was achieved. Similar values were achieved for the A3 and A2/A4 absorbers (Fig. 3, c and d; Table 3).

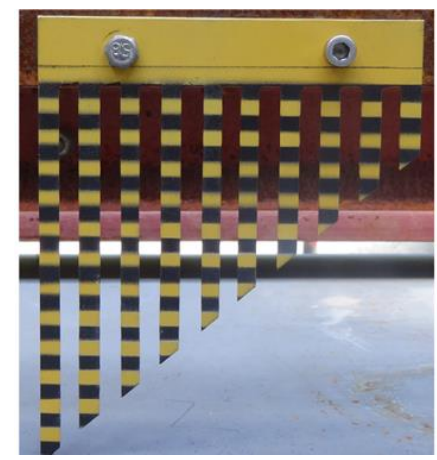

a

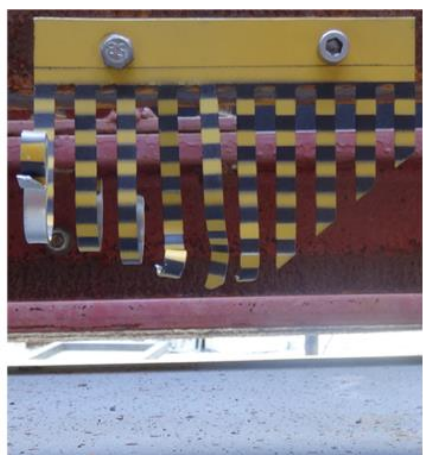

b
Fig. 2 Example appearance of the comb gage before (a) and after the test (b)

Compilation of experimental and numerical results

Table 3

\begin{tabular}{|c|c|c|c|c|c|c|c|}
\hline \multirow{2}{*}{$\begin{array}{c}\text { Charge } \\
\text { weight, } \\
m, \mathrm{~kg}\end{array}$} & \multirow{2}{*}{ Absorber } & \multicolumn{2}{|c|}{ Total deformation of the system, $D_{t}, \mathrm{~mm}$} & \multicolumn{3}{|c|}{ Permanent deformation, $D_{p}, \mathrm{~mm}$} \\
\cline { 3 - 8 } & & Experiment & Simulation & \multicolumn{2}{|c|}{ Experiment } & \multicolumn{2}{c|}{ Simulation } \\
\cline { 2 - 8 } & & Plate $8 \mathrm{~mm}$ & Plate $8 \mathrm{~mm}$ & Plate $8 \mathrm{~mm}$ & Plate $6 \mathrm{~mm}$ & Plate $8 \mathrm{~mm}$ & Plate $6 \mathrm{~mm}$ \\
\hline 1,5 & Without absorber & 101.3 & 90 & 22 & 80.5 & 29 & 87 \\
\hline 1,5 & A1 & 79.1 & 75.5 & 9 & 0 & 0 & 0 \\
\hline 1,5 & A3 & 86.9 & 86.1 & 17,3 & 0 & 9 & 0 \\
\hline 1,5 & A2/A4 & 82.3 & 76.8 & 15 & 0 & 9 & 0 \\
\hline
\end{tabular}

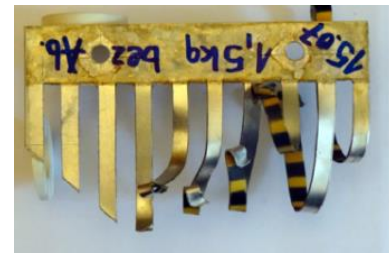

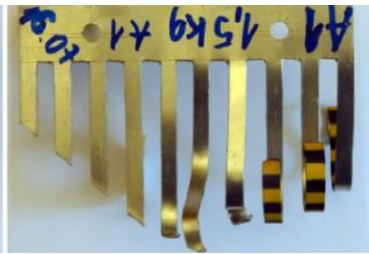

b

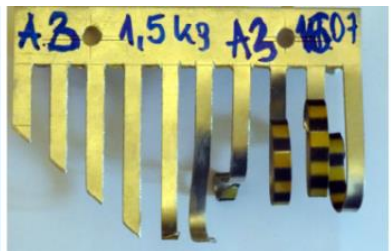

c



d

Fig. 3 Comb gages after tests: a - with no absorber, b - with absorber A1, c - with absorber A3, and d - with absorber A2/A4

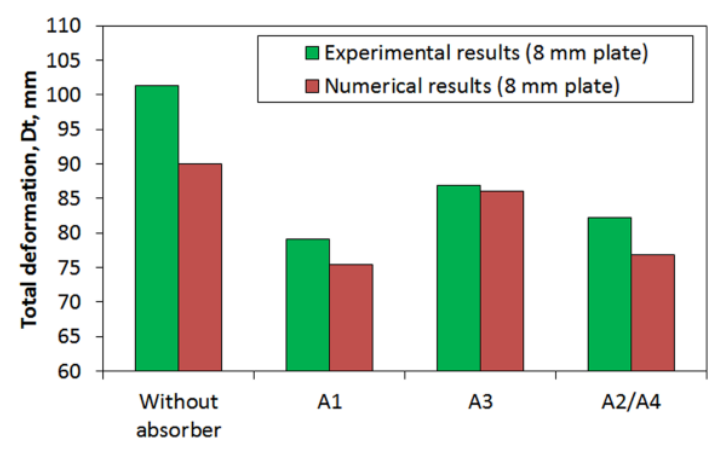

a

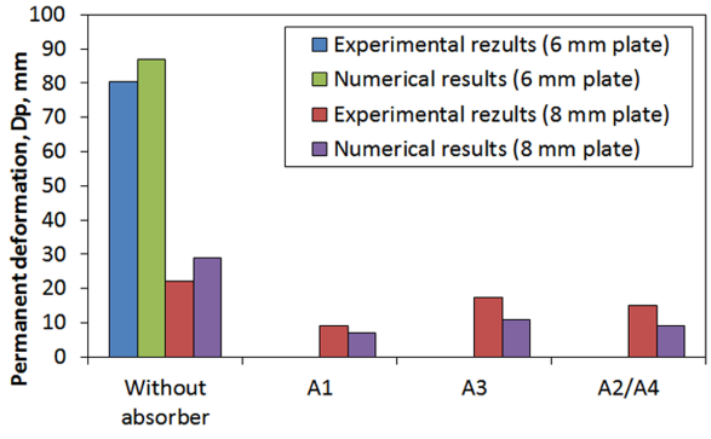

b

Fig. 4 Experimental and numerical deformation results: a - total, and b - permanent deformations of the energy absorbing reference barriers and barriers with absorbers A1, A3, A2/A4

However, plastic strain of the $8 \mathrm{~mm}$ sheet for the A1 absorber, which amounted to $9 \mathrm{~mm}$, is more important. This result, as compared to the plastic strain of the reference divider $(22 \mathrm{~mm})$, lead to the achievement of a $60 \%$ decrease in deformation (Fig. 4, b).

The use of absorbers A3 and A2/A4 resulted in a deformation of the upper plate by 17.3 and $15 \mathrm{~mm}$, respec- tively. In addition, it was observed that the $6 \mathrm{~mm}$ thick plate, in combination with each absorber, did not work within the plasticity range of the material, and consequently no plate deformation took plate (Fig. 4, b). 


\section{Numerical tests of shock wave influence on the pro- tective panel}

Base panel.

Tests conducted on the base panel (Fig. 5) showed that after $0.2 \mathrm{~ms}$, the lower plate hits the upper plate. Due to the energy transfer the upper plate begins to deform. Within ca. $2.5 \mathrm{~ms}$, the plate is bended to the maximum extent. The middle part of the lower plate moves upwards by ca. $162 \mathrm{~mm}$, and for the upper plate - $90 \mathrm{~mm}$ (Fig. 5 b). Once the pressure wave fades, the panel plates vibrate freely.

Permanent deformations of the lower plate amounted to $87 \mathrm{~mm}$, and for the upper plate- $29 \mathrm{~mm}$. Therefore, the deformations are larger than those observed in experimental tests.

Panel with A1 absorber.

The implementation of an absorber element had a significant influence on the course of deformation of armour plates (Fig. 6). In the initial stage, the element bends and absorbs energy. Due to a low level of suppression the energy is then transferred to the upper plate. However, in contrast to the base panel, this occurs on a significantly larger surface. The plate bends evenly and no local embossing occurs on the sheet. Once the extortion ends, the plates and their filling vibrate freely, until the movement stops completely. The main transfer of explosion energy is realised through the absorber element.

The maximum vertical transfer of the upper plate amounted to $75.5 \mathrm{~mm}$, and for the lower plate $-69.1 \mathrm{~mm}$. No permanent deformations were noted on the lower plate. The upper plate bended slightly alongside edges - perma- nent bend amounted to $7 \mathrm{~mm}$. The middle part of the plate remained flat.

Panel with A3 absorber.

For the panel with the A3 absorber a similar reaction of the structure was observed. In this variant's first stage the layer with bushings is being pressed (Fig. 7 - a). After ca. $0.8 \mathrm{~ms}$, it becomes relaxed and transfers the energy to the upper plate. Similar to as in the previous case, the absorber divides the acting forces onto a significantly larger surface as compared to the base panel.

Maximum vertical shift (Fig. 7, b) of the upper plate amounted to $86.1 \mathrm{~mm}$, and for the lower plate -50.9 $\mathrm{mm}$. No permanent deformations were noted for the lower plate. Similarly, to as in the previous variant, the upper plate was bent alongside edges, and the permanent bend of the middle of the plate amounted to $11 \mathrm{~mm}$. Just as for the A1 absorber, a significant part of the plate remained undeformed.

Panel with A2/A4 absorber.

The process of deformation of armour plates and layers of the A2/A4 absorber is similar to the process in variant A1 (Fig. 8, a). The slight difference consists in the fact, that initially only the lower layer of polyurethane is deformed, and then the energy is transferred through the carbon fibre plates to the upper layer of polyurethane. However, the process of upper armour plate deformation is identical in principal.Fig. 8, b shows the course of vertical shifts of the armour plates. Maximum bend of the upper plate amounted to $76.8 \mathrm{~mm}$, and for the lower plate -70.2 $\mathrm{mm}$. Permanent deformation of the upper plate reached the value of $9 \mathrm{~mm}$, and for the lower plate, as in the previous cases, no permanent deformations were observed.

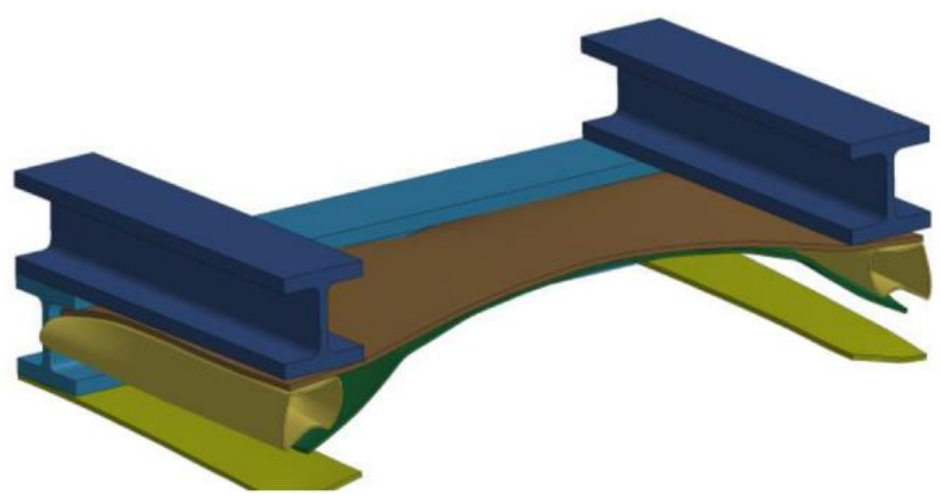

a

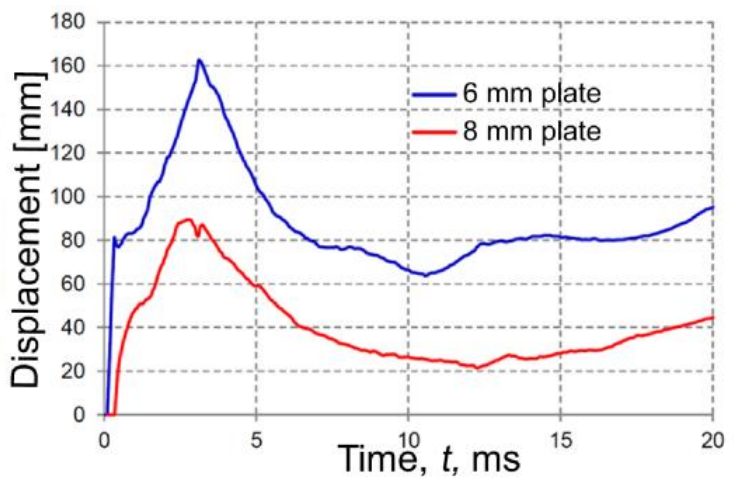

$\mathrm{b}$

Fig. 5 Deformation of base panel $-\mathrm{a}$; central point bend on the lower and upper plate $-\mathrm{b}$

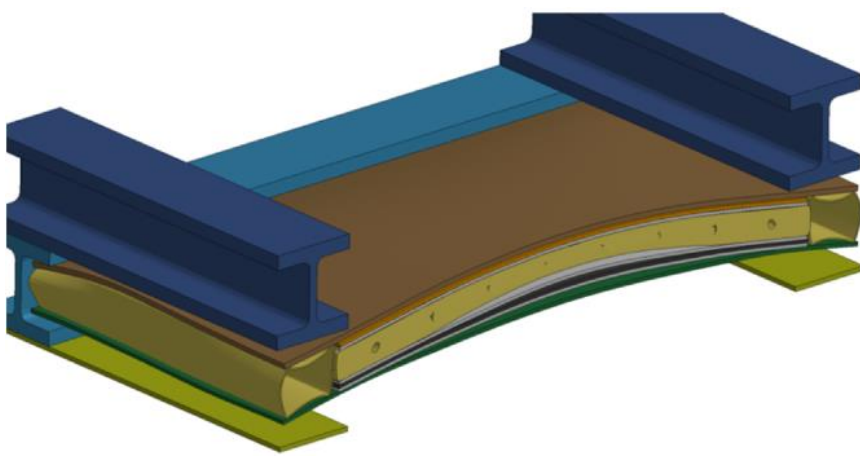

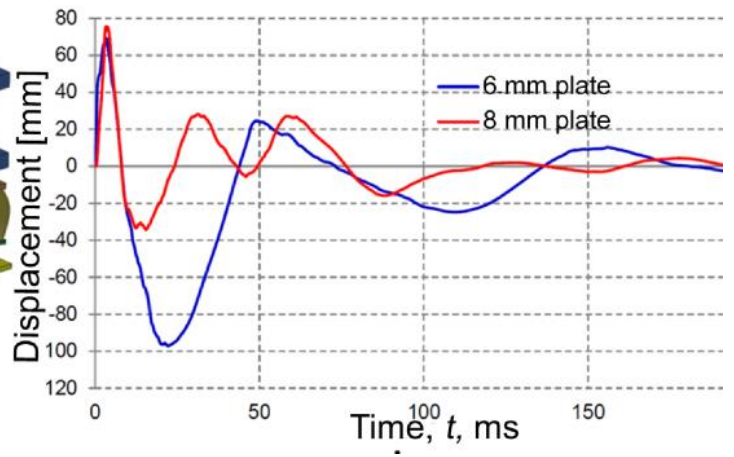

$\mathrm{b}$

Fig. 6 Deformation of the panel with A1 absorber - a; central point bend on the lower and upper plate $-b$ 


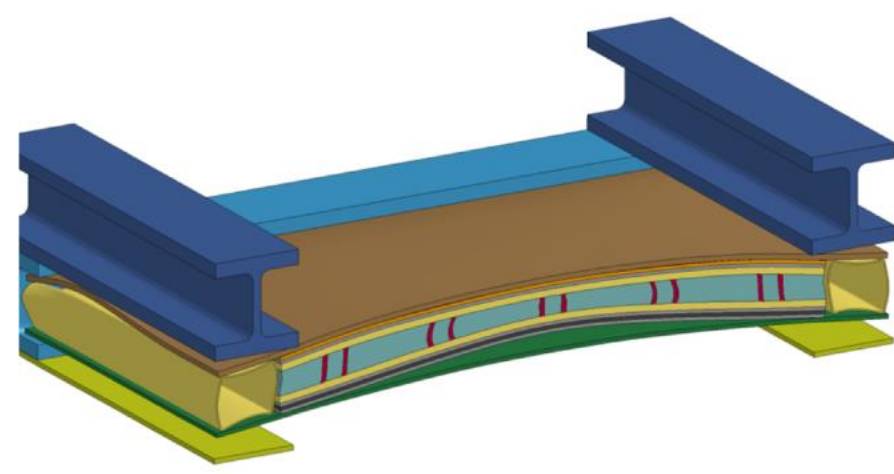

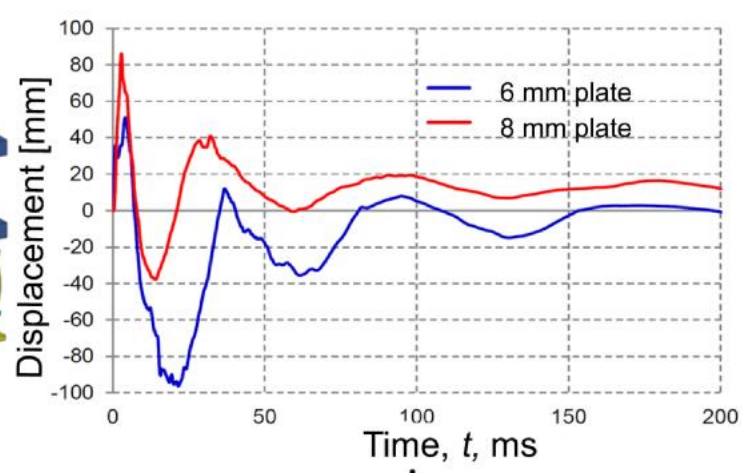

b

Fig. 7 Deformation of the panel with A3 absorber - a; central point bend on the lower and upper plate $-b$

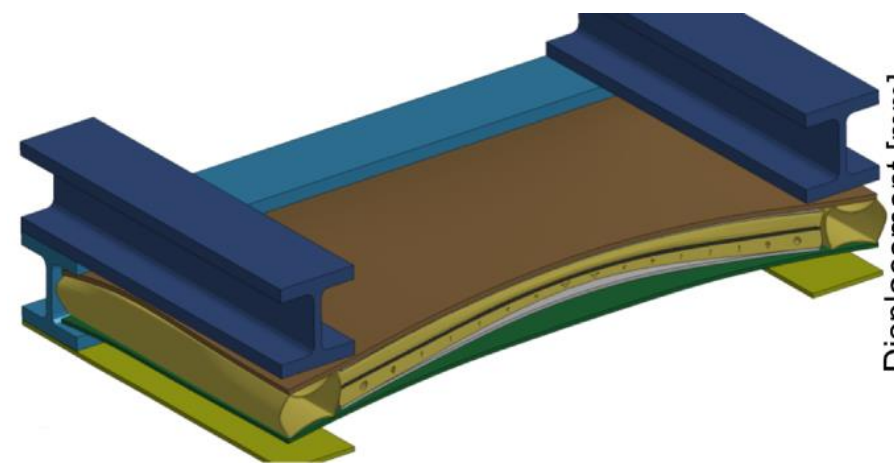

a

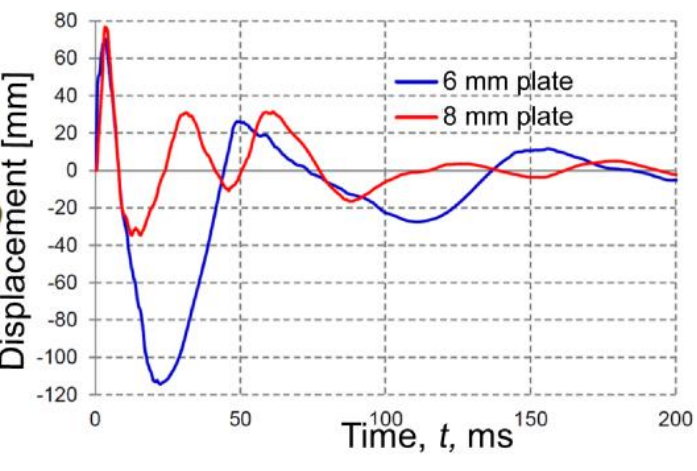

b

Fig. 8 Deformation of the panel with A2/A4 absorber - a; central point bend on the lower and upper plate - b

The difference in the vibration frequency of the upper plate and lower compared absorbers A1 and A2/A4 to the A3 absorber, was associated with the different design of the absorber itself. More rigid construction of the absorber caused an increase in the frequency of vibration of the top plate. The authors have linked it with the excitation system to the formation of harmonic vibration. In the case of a lower density (absorber A3), this phenomenon was not observed.

The result of testing of energy-intensive shields' numerical models with absorbers and reference models showed a high degree of conformity with the experiment conducted on the research station (Fig. 4). The conformity of simulation results for the reference barrier, and with $\mathrm{A} 1$, $\mathrm{A} 3$, and A2/A4 absorbers, as regards the total deformation, reached $88.8 \%, 95.4 \%, 99.1 \%$, and $93.3 \%$ respectively. In the case of permanent deformation (Fig. 4, b) for the upper sheet $(8 \mathrm{~mm})$ the obtained conformity was at the level of $75.9 \%, 77.8 \%, 63.8 \%$, and $60.0 \%$ respectively. For the lower sheet $(6 \mathrm{~mm})$ conformity at the level of $92.5 \%$, $100 \%, 100 \%$, and $100 \%$ was obtained.

These results show that the numerical model was properly validated and may be used in future research with the use of this type of materials.

\section{Processes occurring in shield models generated by explosion - discussion on the obtained test results}

The research shows that the energy of the shock wave caused by the detonation of $1.5 \mathrm{~kg}$ TNT caused maximum deformation of the measured segment of the comb (rod) for the reference energy-intensive divider (without absorbers). The registered value of deformation amounting to $101.3 \mathrm{~mm}$ indicates that high energy was transferred to the comb (Fig. 3, a) through the $8 \mathrm{~mm}$ steel armour plate which was deformed in the first stage (Table 3). This resulted from the fact, that the $6 \mathrm{~mm}$ thick lower steel plate, strained by the explosive force, transferred momentum to the upper plate when they touched. Before the plates touched, the lower plate had deformed by $80 \mathrm{~mm}$ (construction distance of the shield model). Since that moment, both plates were being strained. The upper plate cannot shift, because it is fixed on the edge, but it may still deform. The process of deformation is terminated when the energy is fully dissipated. The maximum strain is the total of elastic and plastic strain of the plates' material. When the plate's shock wave fades, elastic deformation fades as well. Both plates retained only plastic deformation. The value of deformation for the upper plate amounted to 22 $\mathrm{mm}$ (Table 3). The process of energy dissipation in shield models with elastomer absorbers takes a different course, due to higher rigidity of the shield and the construction and properties of absorber's materials. Similarly, to the reference shield two parallel energy dissipation processes may be distinguished. The first is related to the material system momentum rule, and the latter to deformation of individual components of the shield model. Material system is understood as the construction and material of the shield. A subsequent mechanism of flow and gradual dissipation of energy may be observed in the tested models with absorbers. First, the energy from the explosive charge is transferred to the lower steel plate, causing its movement and deformation. Then, the lower plate's momentum is transferred onto the absorber structure, which deforms internally and is stressed. The momentum of the system consisting of the deformed lower plate with the deformed absorber is 
transferred onto the upper plate, causing its elastic and plastic deformation. As in the reference model, the upper plate cannot shift, as it is fixed on the edges. When the flow process of energy from the detonation of the explosive charge stops, a secondary process occurs. The energy, which is stored in the elastically deformed elements of the shield, flows in the opposite direction. This fact is documented by plastic deformation measurements for the upper plate and virtually no deformation of the lower plate in shield models with absorbers (Table 3 ). The smallest registered deformation of the upper plate occurred for the absorber marked with the A1 symbol (Fig. 3, b, Table 3). Due to the rapid pace of processes it is difficult to estimate the exact level of energy absorbed by the absorber. In order to determine which of the tested absorber solutions is the most beneficial, an indirect method was assumed, i.e. the difference between the value of deformation of the upper steel plate of the reference shield and the deformation value of this plate for the shield with absorber. The value of the difference is the measure of the energy suppressed by the absorber. Fig. 9 shows the value of the calculated differences for the tested absorbers.

In conclusion, the energy from the explosive material was consumed by the movement of the lower plate and its elastic deformation, the total shift of the temporarily touching masses of the absorber and the lower plate, the elastic deformation of the absorber's material, and the deformation of the upper plate.

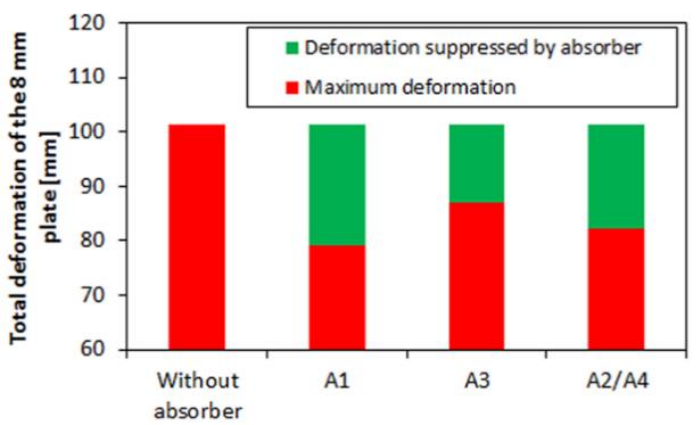

Fig. 9 Comparison of obtained plastic deformation values in upper shield plates with various absorbers in relation to the reference shield; green denotes the value of deformation suppressed by the absorber

\section{Conclusions} shown that:

Based on the tests described above, it has been

1. It is possible to estimate the energy absorbed by the energy absorber in the form of linear dimension as the difference between the maximum deformation of the system with no absorber and the system with the absorber under assessment.

2. The tests performed show that the energy of the shock wave acting on a spatial system of plates (reference barrier) is absorbed by elastic and plastic deformations of the lower and upper plates, resulting in a large total deformation of the system.

3. The use of deformable absorbers in a spatial system resulted in the upper plate deformation reduction by $22 \%$.

4. The use of absorbers fabricated of elastic-plastic materials should significantly improve the safety of the crew inside the vehicle by preventing penetration of the energy released by charge detonations under the vehicle.

5. The result of testing of energy-intensive barrier models with absorbers and the reference barrier showed a high degree of conformity with the experiment conducted on the research station.

6. Conformity of simulation results for the reference barrier, and with absorbers as in the case of the total deformation, reached up to $99 \%$.

7. Permanent deformation for the upper sheet reached conformity level at $77 \%$. The conformity for the lower sheet reached as much as $100 \%$.

\section{Acknowledgments}

The work was supported by the European Regional Development Fund in Poland (project: "Manufacturing technologies for the new generation composite impact energy absorbers", project no. POIG.01.03.01-14031/12).

\section{References}

1. Genson, K.W. 2006. Vehicle shaping for mine blast damage reduction, University of Maryland, College Park. Master of Science.

2. Mori, L. F.; Lee, S.; Xue, Z. Y.; Vaziri, A.; Queheillalt, D. T.; Dharmasena, K.P.; Wadley, H. N. G.; Hutchinson, J. W.; Espinosa, H. D. 2007. Deformation and fracture modes of sandwich structures subjected to underwater impulsive loads, Journal of Mechanism of Material and Structure 10: 1981-2006. https://doi.org/10.2140/jomms.2007.2.1981.

3. Xue, Z.; Hutchinson, J. W. 2004. A comparative study of impulse-resistant metal sandwich plates, International Journal of Impact Engineering 30: 1283-1305. https://doi.org/10.1016/j.ijimpeng.2003.08.007.

4. Wei, Z.; Deshpande, V. S.; Evans, A. G.; Dharmasena, K. P.; Queheillalt, D.T.; Wadley, H. N. G.; Murty, Y.V., Elzey, R.K., Dudt, P., Chen, Y., Knight, D.; Kiddy, K. 2008. The resistance of metallic plates to localized impulse, Journal of the Mechanics and Physics of Solids 56: 2074-2091. https://doi.org/10.1016/j.jmps.2007.10.010.

5. Rimoli, J.J.; Talamini, B.; Wetzel, J.J.; Dharmasena, K.P.; Radovitzky, R.; Wadley, H. N. G. 2011. Wet-sand impulse loading of metallic plates and corrugated core sandwich panels, International Journal of Impact Engineering 38: 837-848.

5. Rimoli, J.J.; Talamini, B.; Wetzel, J.J.; Dharmasena, K.P.; Radovitzky, R.; Wadley, H. N. G. 2011. Wetsand impulse loading of metallic plates and corrugated core sandwich panels, International Journal of Impact Engineering 38: 837-848.

https://doi.org/10.1016/j.ijimpeng.2011.05.010.

6. Kuchta, W. 2014. Searching for the best. Przegląd Sił Zbrojnych 2: 13-18 (in Polish).

7. Stewart, L. K.; Freidenberg, A.; Rodriguez-Nikl, T.; Oesterle, M.; Wolfson, J.; Durant, B.; Arnett, K.; Asaro, R. J.; Hegemier, G. A. 2014. Methodology and validation for blast and shock testing of structures using high-speed hydraulic actuators, Engineering Structure 70: $168-180$.

https://doi.org/10.1016/j.engstruct.2014.03.027. 
8. Sohel, K. M. A.; Liew, J. Y. R.; Zhang, M. H. 2011. Analysis and design of steel-concrete composite sandwich systems subjected to extreme loads, Front of Architect and Civil Engineering in China 5: 278-293. https://doi.org/10.1007/s11709-011-0120-z.

9. AEP-55. Volume 2. Allied Engineering Publication. Procedures for Evaluating the Protection Level of Armored Vehicles. August 2011.

10.(TOP) 2-1-007. Test Operation Procedure. Dynamic Displacement Measurement. Ballistic Instrumentation Division (TEDT-AT-SLB)

L. Starczewski, M. Gmitrzuk, D. Danielewicz, K. Szcześniak, R. Nyc

\section{STUDY OF THE SHOCK WAVE EFFECT ON THE DEFORMATION OF THE VEHICLE BOTTOM USING DEFORMABLE ENERGY ABSORBERS}

S u m m a r y

The paper reports a study on the effect of a shock wave generated during the detonation of $1.5 \mathrm{~kg}$ TNT on the deformation of a multi-layered energy absorber. The experiments were carried out using a custom- designed testing station. The detonation of the charge was performed using a steel plate with a blind hole in accordance with the requirements of the NATO (North Atlantic Treaty Organization) AEP -55 (Allied Engineering Publication) volume 2 document. In the tests, the total and plastic deformations of the plate modelling the basic armour of the lower part of the vehicle in configurations without and with a shock wave absorbing element (energy absorber) were measured. The comb gage method reported by the US Army Developmental Test Command was used in measurements of the total deformation of the model. The study has shown that an appropriate design of the energy absorber and the use of suitable materials in its fabrication allow the total deformation to be reduced. Moreover, in this article numerical simulations of the deformation phenomenon of the multilayered energy absorbers were shown. Numerical simulations have shown high numerical model compliance compared to the experimental studies. In the studies were achieved about 99 percent numerical with the real model correlation.

Keywords: Shock wave, blast energy absorbers, deformation, detonation, numerical simulation.

Received February 05, 2016 Accepted December 07, 2017 